\title{
ESTIMATION RISK MODEL AS A NEW METHOD OF INSULIN INDUCED LIPOHYPERTROPHY DIAGNOSTICS IN DIABETIC PATIENTS
}

Volkova N.I., Davidenko I.Y., Porksheyan M.I., Rudakova J.A.

Rostov State Medical University, Rostov-on-Don, Russian Federation, dim3.rostgmu@gmail.com

Objectives:

to develop the estimation risk model of insulin induced lipohypertrophy (LH) in diabetic patients
Material and methods:

140 diabetic patients, who had been under the treatment

with insulin a mean 8 years

2 groups:

I - 117 patients with LH

II - 23 diabetics without pathologic

areas of subcutaneous fat
Statistics:

- rank correlation coefficients

- binary logistic regression

- ROC-analysis and measure AUC, $p<0,05$

Results:

- 14 all known RF

- 14 additional RF

\begin{tabular}{|c|c|c|}
\hline Risk factor & AUC & $95 \% \mathrm{Cl}$ \\
\hline Painfullness of injections & 0,686 & 0,598 to 0,766 \\
\hline Quantity of injection by one needle & 0,666 & 0,577 to 0,747 \\
\hline Duriation DM & 0,656 & 0,566 to 0,738 \\
\hline Duriation of insulinotherapy & 0,656 & 0,567 to 0,739 \\
\hline Presence of drop on the tip of the needle & 0,632 & 0,542 to 0,716 \\
\hline Rotation of injection sites & 0,623 & 0,532 to 0,707 \\
\hline Needle retention in skin after injection & 0,644 & 0,554 to 0,726 \\
\hline Body mass index & 0,640 & 0,549 to 0,723 \\
\hline Diabetic mellitus education & 0,542 & 0,451 to 0,631 \\
\hline Usage of human insulin & 0,571 & 0,480 to 0,659 \\
\hline
\end{tabular}

\section{II stage}

\begin{tabular}{|l|c|c|}
\hline \multicolumn{1}{|c|}{ Risk factor } & $\begin{array}{c}\text { Prediction } \\
\text { coefficient }\end{array}$ & Value \\
\hline Painfullness of injections & 1,62 & $\mathrm{~K}_{6}$ \\
\hline Quantity of injection by one needle & 0,76 & $\mathrm{~K}_{7}$ \\
\hline Duriation DM & 0,31 & $\mathrm{~T}_{1}$ \\
\hline Duriation of insulinotherapy & 0,27 & $\mathrm{~T}_{2}$ \\
\hline Presence of drop on the tip of the needle & 0,13 & $\mathrm{~K}_{4}$ \\
\hline Rotation of injection sites & $-0,04$ & $\mathrm{~K}_{3}$ \\
\hline Needle retention in skin after injection & $-0,21$ & $\mathrm{~K}_{5}$ \\
\hline Body mass index & $-0,22$ & $\mathrm{nMT}$ \\
\hline Diabetic mellitus education & $-1,46$ & $\mathrm{~K}_{1}$ \\
\hline Usage of human insulin & $-11,38$ & $\mathrm{~K}_{2}$ \\
\hline
\end{tabular}

$\mathrm{p}=\frac{e^{Z}}{1+e^{Z}} \quad \mathrm{z}=17-0,22 \mathrm{xT}_{1}+0,27 \mathrm{xT}_{2}+0,31 \mathrm{xhMT}-11,38 \mathrm{xK}_{1}-0,21 \mathrm{xK}_{2}-0,04 \mathrm{xK}_{3}+0,76 \mathrm{xK}_{4}-1,46 \mathrm{xK}_{5}+1,62 \mathrm{xK}_{6}+0,13 \mathrm{xK}_{7}$

\section{III stage}

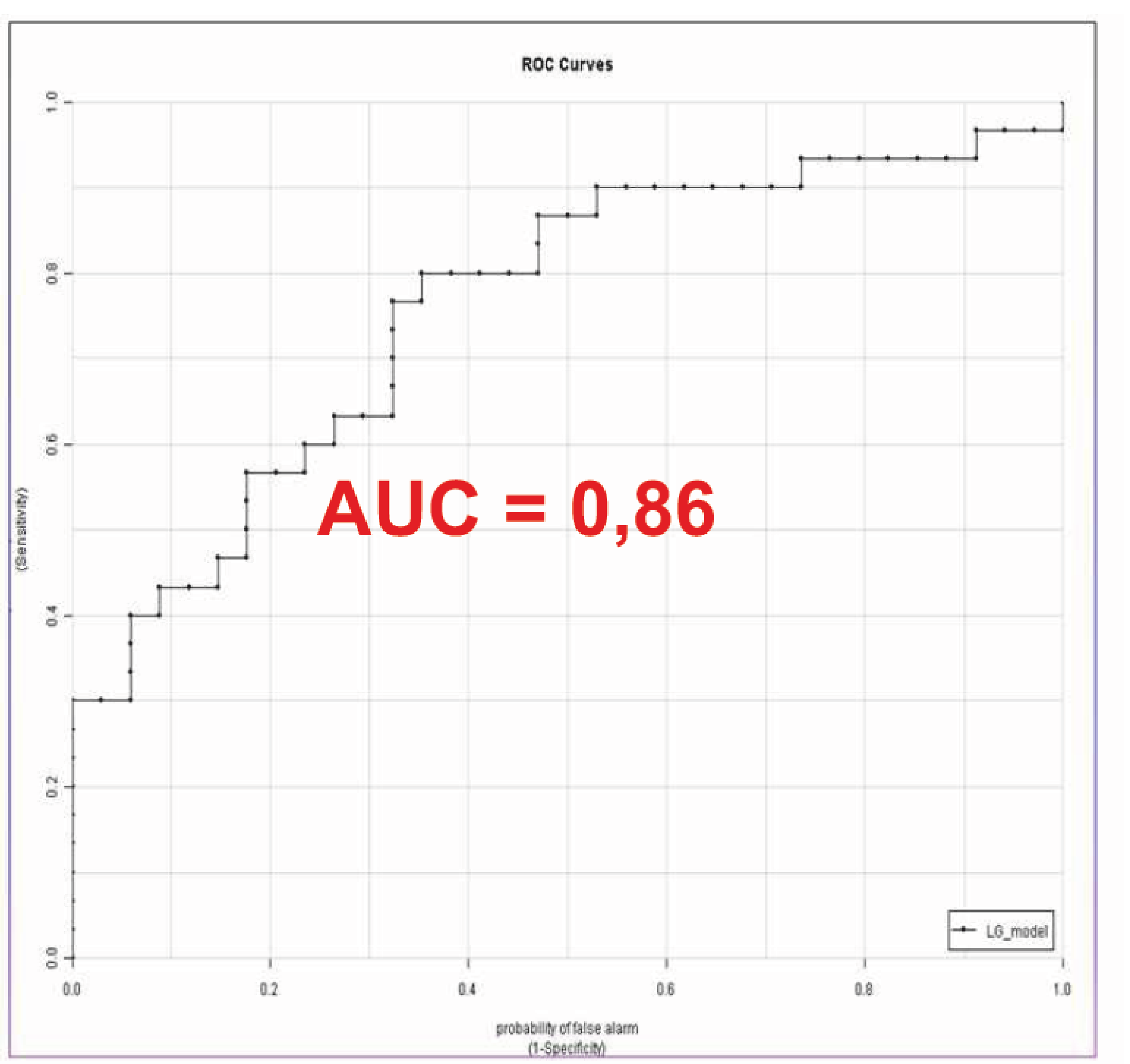

$$
\mathrm{p}<0,5
$$

low LH risk $p \geq 0,5$

high LH risk

\section{Clinical case}

Woman L., 59 years, is diabetic patient during 8 years, who is under the treatment with insulin last 2 years. She was succesfully studied Diabetic mellitus education 2 years ago. Patient uses human insulin, rotation of injection sites is haphazardly, needles change once in day, needle retention in skin after injection is less than $\mathbf{5}$ second. Sometime insulin injection is painful. There is a presence of drop on the tip of the needle after injection. Physical examination: there is no palpabable and visible site of $\mathrm{LH}$, body mass index is $28 \mathrm{~kg} / \mathrm{m} 2$

\begin{tabular}{|c|c|c|c|c|c|r|r|r|r|r|}
\hline $\mathrm{T}_{1}$ & $\mathrm{~T}_{2}$ & \multicolumn{1}{c|}{ ИMT } & $\mathrm{K}_{1}$ & $\mathrm{~K}_{2}$ & $\mathrm{~K}_{3}$ & $\mathrm{~K}_{4}$ & $\mathrm{~K}_{5}$ & $\mathrm{~K}_{6}$ & $\mathrm{~K}_{7}$ & $\mathrm{p}$ \\
\hline$-0,22$ & 0,27 & 0,31 & $-11,38$ & $-0,21$ & $-0,04$ & 0,13 & 0,76 & $-1,46$ & 1,62 & \\
\hline 8 & 3 & 28 & 1 & 1 & 5 & 3 & 1 & 1 & 3 & $\mathbf{0 , 8 8}$ \\
\hline
\end{tabular}

$p=0,88 \geq 0,5$

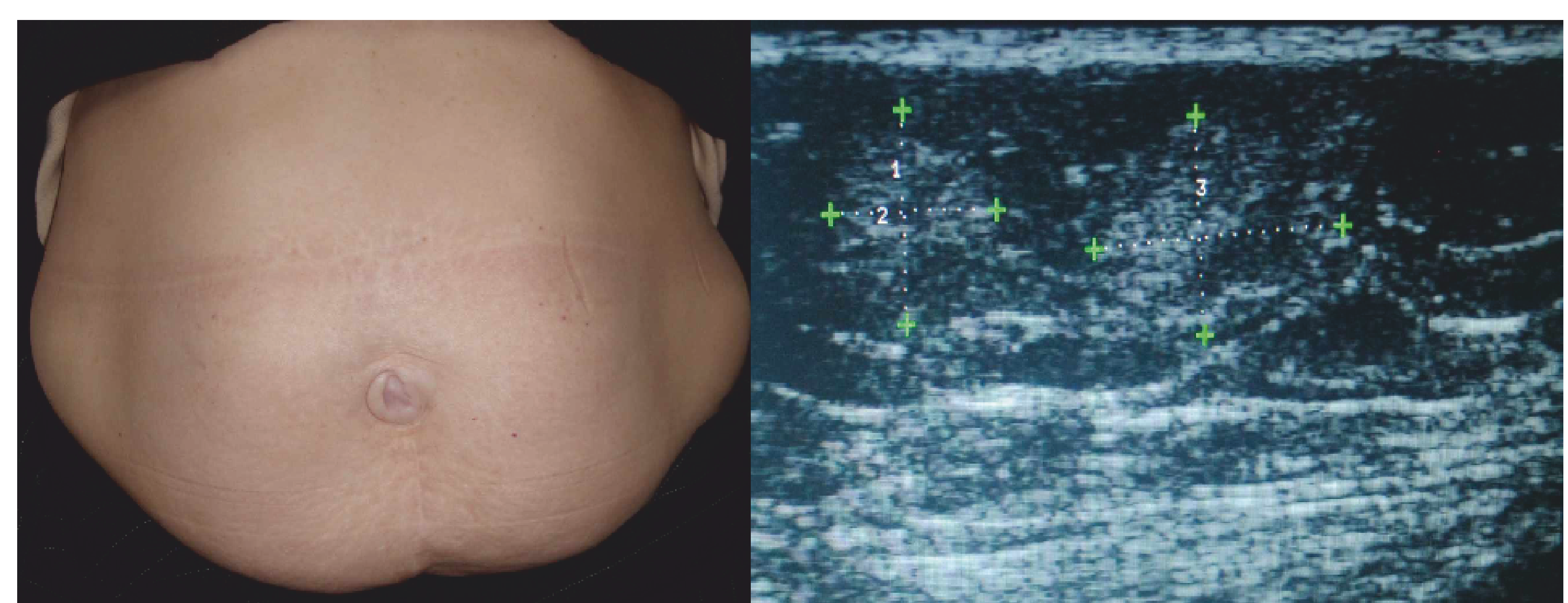

Conclusions:

Nowadays, LH remains severe insulinotherapy complication. Primary prevention is necessary for diabetic patients with pathologic areas of subcutaneous fat.
Therefore, we developed the estimation risk model with good quality and high predictive value $(86 \%)$ for diabetic patients who are under the treatment with insulin. 